\title{
PHOTOLETTER TO THE EDITOR
}

\section{Scarring alopecia resulting from pyoderma gangrenosum of the scalp}

\author{
Akilahyel A. Ndahi ${ }^{1}$, Chubado Tahir ${ }^{2}$, Haruna A. Nggada ${ }^{3}$ \\ Department of Medicine ${ }^{1}$, Plastic Surgery Unit ${ }^{2}$ and Histopathology ${ }^{3}$, University of Maiduguri Teaching Hospital, P.M.B, \\ 1414, Bema Road, Maiduguri, Borno State, Nigeria.
}

\section{Corresponding author:}

Dr. Akilahyel A. Ndahi, Department of Medicine, University of Maiduguri Teaching Hospital, P.M.B. 1414, Bama Road, Maiduguri, Borno State, Nigeria. Email: hanaggada@yahoo.com

\section{Abstract}

Pyoderma gangrenosum is an uncommon ulcerative cutaneous condition of uncertain aetiology. It is a disease that causes tissue to become necrotic, leading to deep ulcers. We report a case of pyoderma gangrenosum localized at the scalp, which is an unusual location. After 16 months of treatment with prednisolone $40 \mathrm{mg}$ daily, methotrexate 15 mg weekly, ciprofloxacin $500 \mathrm{mg}$ and honey dressing the indurated elevated ulcer margins flattened and the ulcer healed with scarring of the entire scalp. (J Dermatol Case Rep. 2012; 6(1): 34-35)

\section{Key words:}

adolescent, cicatricial alopecia, ciprofloxacin, honey, methotrexate, prednisolone, scalp, scar

Pyoderma gangrenosum (PG) is an uncommon ulcerative cutaneous condition of uncertain aetiology. The disease causes tissue necrosis, leading to deep ulcer, and is most commonly localized peripherally on lower and upper limbs., ${ }^{1,3}$ PG has been associated with several systemic diseases including ulcerative colitis, Chrohn's disease, Rheumatoid arthritis, polyarthritis, monoclonal gammopathy and myeloproliferative disease. ${ }^{1,2,3}$

We report a case from our hospital. A 17-yearold boy presented at the Plastic Surgery unit, U.M.T.H with a 10-year history of extensive scalp ulcer. According to anamnesis, it started as a nodule at the vertex of the head which was painless but itched occasionally. The nodule increased in size and four months later ulcerated suddenly. The scalp ulcer increased in size progressively and almost the whole scalp was involved within one year of diseases course (Fig. 1). The patient used traditional medicaments (both oral and topical) with no improvement. About one year before presentation he was seen at another

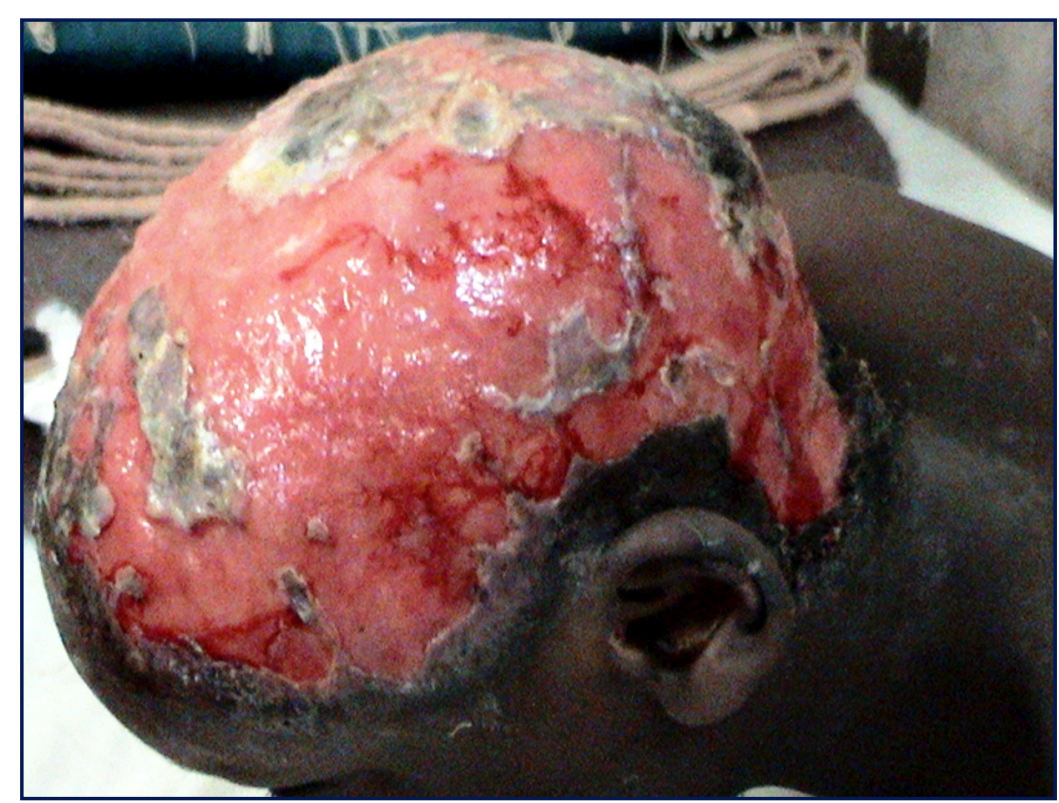

Figure 1

Extensive ulceration of the scalp in the course of pyoderma gangrenosum. The ulcer healed with scarring alopecia as residue. 
hospital, where skin grafting of the ulcer was done. There was initial healing, but within 6 months of the grafting the whole skin graft was lost. On examination, the scalp almost entirely ulcerated. The ulcer was associated with purulent foul-smelling discharge and had necrotic floor with raised indurated grayish margins. There was no peripheral lymphadenopathy. Systemic examination was essentially normal.

Laboratory abnormalities were: $\mathrm{WBC}=10.5$ $X 109 / \mathrm{l}, \mathrm{PCV}=0.28, \mathrm{ESR}=100 \mathrm{~mm} / \mathrm{hr}$. Wound swab showed no bacterial growth after 72 hours incubation, and no fungal infection. Histology of biopsy of the ulcer shows features of chronic non-specific inflammation.

Initial treatment given were antibiotics (amoxicillin clavulanate and metronidazole), haematinics and daily wound dressing with honey. Despite the treatment, the ulcer progressed in size over subsequent months, to involve the whole scalp. After the diagnosis of pyoderma gangrenosum was established, the patient was placed on prednisolone $40 \mathrm{mg}$ daily, methotrexate 15 mg weekly, and ciprofloxacine $500 \mathrm{mg}$ bd, with a dailynatural honey dressing topically applied to the scalp ulcer. The indurated elevated ulcer margins flattened and the ulcer healed progressively. Within 16 months of commencing this new treatment the ulcer healed completely. The dose of prednisolone was tapered. On oral prednisolone $25 \mathrm{mg}$ daily, eight months after discharge the patient experiences recurrent ulceration of about 1 to $2 \mathrm{~cm}$ in diameter on the vertex.

Scalp is an unusual location for pyoderma gangrenosum, with only few cases reported worldwide. ${ }^{4}$ Most of these patients were adults, 4278 years of age and most of them responding well to either corticosteroids, cyclosporine A or other types of immunosupression. ${ }^{4}$ There are historical reports of pyoderma gangrenosum of the scalp in adolescent patients with dark skin phototypes. ${ }^{5}$ Almost all these patients had a severe systemic diseases or malnutrition and anemia.
In pyoderma gangrenosum pathergy (occurrence of the lesion at sights of trauma or other skin rash) occurs in at least $20 \%$ of patients. ${ }^{6}$ The disease usually begins with an acute phase of necrotic pustule or furuncle and can evolve to a large and deep necrotic ulcer with violaceous border and a surrounding halo of erythema. ${ }^{7}$ The irregular border is elevated and redish or purplish and undermined. Acute onset are usually associated with considerable toxicity and fever. The course extends over several weeks and months and the growth of ulcer may be rapid, invoIving large areas of the body within a few days, or indolent and slow.

Our case had a long history before presentation, after seeking treatment from natural medicine and traditional health healers without success. Additionaly unsuccessful skin grafting was performed, which might have additionally caused a pathergic reaction. After adequate therapy, the patient developed a scalp scar, reasembling scarring alopecia, and continues to have recurrent small island of ulceration on the vertex eight months after discharge from the hospital despite taking $25 \mathrm{mg}$ prednisolone tablets daily. This case shows an unusual cause of scarring alopecia.

\section{References}

1. Dabade TS, Davis MD. Diagnosis and treatment of the neutrophilic dermatoses (pyoderma gangrenosum, Sweet's syndrome). Dermatol Ther. 2011; 24: 273-284. PMID: 21410617.

2. Wollina $U$, Haroske G. Pyoderma gangraenosum. Curr Opin Rheumatol. 2011; 23: 50-56. PMID: 21037478.

3. Alese OB, Irabor DO. Pyoderma gangrenosum and ulcerative colitis in the tropics. Rev Soc Bras Med Trop. 2008; 41: 664-667. PMID: 19142449.

4. Poenitz N, Tadler D, Klemke CD, Glorer E, Goerdt S. Ulceration of the scalp: a unique manifestation of pyoderma gangrenosum. J Dtsch Dermatol Ges. 2005; 3: 113-116. PMID: 16351014.

5. Goreti Catorze M, Pereira F, Fonseca F, Morbey A, Assis Pacheco F. Pyoderma gangrenosum associated with sclerosing cholangitis, type 1 diabetes mellitus and ulcerative colitis. J Eur Acad Dermatol Venereol. 2001; 15: 257-259. PMID: 11683294.

6. Varol A, Seifert O, Anderson CD. The skin pathergy test: innately useful? Arch Dermatol Res. 2010; 302: 155-168. PMID: 20012749.

7. Ahronowitz I, Harp J, Shinkai K. Etiology and Management of Pyoderma Gangrenosum: A Comprehensive Review. Am J Clin Dermatol. 2012 Feb 23. doi: 10.2165/11595240-000000000-00000. [Epub ahead of print]. PMID: 22356259. 